\title{
Darting Primates: Steps Toward Procedural and Reporting Standards
}

\author{
Matias Fernandez-Duque ${ }^{1}$ (D) \\ Colin A. Chapman ${ }^{2,3} \cdot$ Kenneth E. Glander ${ }^{4}$. \\ Eduardo Fernandez-Duque ${ }^{1,5,6}$
}

Received: 27 December 2016 / Accepted: 10 April 2017 /Published online: 21 April 2017

(C) Springer Science+Business Media New York 2017

\begin{abstract}
Darting, a common method of capturing wild primates, poses risks to the individuals that must be appropriately minimized. A recent article in the International Journal of Primatology by Cunningham et al. (International Journal of Primatology, 36(5), 894-915, 2015) presented a literature review of the reporting of darting procedures in primatology and anonymously surveyed primatologists on darting methods and their effects, to report general trends in the field. We quantitatively reexamined 29 articles described by the authors as having information on fatalities and/or injuries. We think that the various body masses of primates $(1 \mathrm{~kg}-150 \mathrm{~kg})$, along with their locations and habitat types, and the degree of experience of the darting team, should be considered when estimating mortality and injury rates, and thus preclude the computation of an average mortality value across taxa. Nevertheless, we computed an average (mean) for comparison with the previous analyses. Our mean estimated mortality rate was $2.5 \%$ and the mean estimated injury risk was $1.5 \%(N=21$ articles). Thus, our estimated mortality rate is smaller than the combined mortality and injury rate of 5\% reported by Cunningham et al.
\end{abstract}

Handling Editor: Jessica Rothman.

Electronic supplementary material The online version of this article (doi:10.1007/s10764-017-9963-z) contains supplementary material, which is available to authorized users.

Matias Fernandez-Duque

matiasfduque@gmail.com

1 Department of Anthropology, Yale University, New Haven, CT 06511, USA

2 Department of Anthropology and McGill School of Environment, McGill University, 855

Sherbrooke Street West, Montréal, Québec H3A 2T7, Canada

3 Wildlife Conservation Society, Bronx, NY 10460, USA

4 Evolutionary Anthropology, Duke University, Durham, NC 27708-9976, USA

5 Fundación ECO, Formosa, Argentina

6 Universidad Nacional de Formosa, Av. Dr. Gutnisky 3200, Herradura, Formosa, Argentina 
(International Journal of Primatology, 36(5), 894-915, 2015) and smaller than the mortality rates of medium-sized terrestrial mammals they used for comparison. Our study strongly suggests the critical need for more data to be analyzed in a standardized fashion.

Keywords Best practices $\cdot$ Capture $\cdot$ Ethics $\cdot$ Methods $\cdot$ Risk

\section{Introduction}

Darting is a common method of capturing primates. Because darting poses risks to the individuals being captured there are specific considerations that are a function of the species size, habitats, and behavior. A recent article in the International Journal of Primatology anonymously surveyed primatologists on darting methods and their effects on primates, and conducted a literature review to assess the reporting trends of darting methods and results (Cunningham et al. 2015). The authors report that in only 18 of 111 articles $(16.2 \%)$ documenting darted primates did researchers include what they considered sufficiently detailed darting procedures and they call for more detailed reporting of darting procedures in publications. From the data included in these 18 articles, they estimated that 33 of ca. 654 darting events resulted in serious complications, injuries, or deaths. They consider this estimated 5\% rate, which includes both mortality and injuries, "alarming" and compare it to darting protocols that consider mortality rates of large, terrestrial mammals $>2 \%$ unacceptable.

An assessment of the current state of darting in primatology and the risks associated with it is necessary and welcome. The revising and improvement of capture and darting techniques must be a regular procedure for any primate capture project, as well as for the field of primatology in general. Reducing the injury and mortality risks associated with darting is a basic way of improving the quality of the research; therefore, an evaluation of the published data on darting procedures is an important and necessary step. Increased details on the methodological procedures for darting primates, including information on injuries and fatalities, can only help improve darting methods and reduce the risks.

Our ultimate goal is the same as that of Cunningham et al. (2015), to contribute to developing a system in which experienced primatologists can make their knowledge available to others and to develop protocols that substantially reduce direct, indirect, and delayed mortality of immobilized primates. The need for more systematically reported data is illustrated when considering the diversity of the primates we study, the experience of the research team, and the cultural context in which the protocols are implemented. But because of that diversity, we think it is necessary to analyze the published data per study, combining data across studies only after considering factors that may make the combination and/or comparison unwarranted.

To illustrate the limitations of existing data, we quantitatively reanalyzed the 29 articles described by Cunningham et al. (2015) as having information on fatalities and/ or injuries ( $26 \%$ of all articles considered). The objectives were 1 ) to reanalyze the data contained in the 18 articles classified as having detailed information on injuries, deaths, and procedures; 2) to expand the analyses by incorporating 11 articles classified as including general information on fatalities and procedures; and 3) to propose that a single quantitative estimate of death or injury for all primates is neither informative nor helpful. 


\section{Methods}

We reanalyzed 29 of the articles considered in Cunningham et al. (2015): 18 articles assessed as having detailed information on darting procedures and 11 with information on the rate of fatalities, other health problems, and general information on procedures (Cunningham and colleagues kindly provided us full citations for these 11 articles). These articles were selected by the authors from a set of 111 articles identified through searches and ranked for the level of information on darting procedures, from most comprehensive (1) to no detail (5).

We sought to quantitatively analyze the injuries and mortality reported in the literature, a different objective from that of Cunningham et al. (2015), whose stated goal was to examine reporting trends in darting. Owing to this difference, we excluded 3 of the 18 articles in Category 1 and 5 of the 11 in Category 2 that may have been appropriate to include in an analysis of reporting trends, but not in an analysis of injuries and mortality. Specifically, we excluded articles in which the health of the darted primates was compromised before darting, as we believe this to be a conflicting factor in analyzing the injury and mortality risk of darting. We excluded for this reason Sleeman et al. (2000) and Hyeroba et al. (2011). In the first study, $100 \%(N=26)$ of the individuals had some form of complication or medical issue before being darted; in the second study, the health situation was the reason for darting this male chimpanzee. We also excluded 5 of the 11 articles in Category 2 in which the reported dartings were the same ones described in an already included article to avoid considering the same data twice. Fernandez-Duque and Erkert (2006) was excluded because the individuals darted are the same ones described in Fernandez-Duque and Rotundo (2003). Kappeler and Erkert (2003), Ostner and Kappeler (1999), Port et al. (2009), and Wimmer and Kappeler (2002) report the same captured red-fronted lemurs (Eulemur fulvus rufus) as those described in Ostner and Kappeler (2004), 98 individuals captured between 1996 and 2002; we considered only the latter study. Akinyi et al. (2013) report captured individuals that belonged to the same population described in Tung et al. (2011). We include in our analyses the 101 individuals reported in the latter article.

We summarized the information in the remaining 21 articles as follows. We produced estimates per study first, only then obtained averages (mean) across studies. For each article, we noted the number of individuals darted (when reported) and captured. Although all primates hit with a dart are at risk of darting, only six articles report the number of individuals darted. Because our objective is to quantify the risks of darting as a primate capture technique, we used the number of reported captures in our analyses. To consider the fact that primates are often recaptured, we focus on the number of captures rather than the number of individuals. Thus, a "capture" refers to the event of a primate being physically retrieved after being darted.

We also considered the retrieval methods used after the individual had been darted. The retrieval of immobilized primates was divided into three main categories: 1) fell to ground, 2) caught when falling, or 3) retrieved from tree by a researcher. This is important, because very frequently darted individuals need to be retrieved by shaking branches or climbing the tree and grabbing them. Ignoring this frequent retrieval method can lead to an inaccurate or misleading success rate for capturing darted individuals. In addition, because many of the primates that we study fall naturally without the fall being fatal (Schultz [1937] found that 9\% of adult wild great ape 
skeletons had healed fractures), we considered that the risk of darting is best assessed by quantifying the number of individuals injured as a result of the actual darting, rather than using falling as a metric for risk As explained previously, using the number of individuals not caught when falling neglects the number of individuals captured without risk from falling. Fatal injuries that caused the primate to later die were not counted as injuries, but as deaths.

All the information on darting analyzed during the current study was obtained from published articles and is therefore publicly available. All data generated during this study are included in this published article and in the Supplementary Electronic Material (ESM) Table SI.

\section{Results}

The 21 articles we considered describe 936 captures and a minimum of 986 darting events. The mean mortality rate was $2.5 \%(\mathrm{SD}=4.0, N=21$ articles, Table I). Eighteen deaths were reported, 16 of which can be directly attributed to the darting. Of the remaining two, one howler death was caused by ether overdose during handling (Scott et al. 1976) and one pregnant female baboon fell ca. $4 \mathrm{~m}$, showed no signs of injury before or after, and was observed 2 days later carrying a dead infant (Melton 1980).

The nonfatal, serious injury rate mean was $1.5 \%$ ( $\mathrm{SD}=3.3, N=21$ articles). Eight injuries were reported. In one study 13 individuals required artificial respiration (Scott et al. 1976) and three studies described primates having problems with thermoregulation (Glander et al. 1991; Hiong et al. 1996; Lemos de Sá and Glander 1993). Two of the eight injuries were superficial wounds and described as "slight" (Olupot 1999). Regardless of the severity of the injury, all injured individuals were reported to have made a full recovery.

The percentage of injuries and deaths varied considerably (range: 0-14\%) among the 15 articles providing detailed information (Table I, Category 1 of Cunningham et al. 2015 ). Serious injuries occurred in $2.0 \pm 3.8 \%$ (mode: 0 ) of the capturing events and deaths in $3.3 \pm 4.5 \%$ (mode: 0 ) of them. These articles describe 592 captures and at least 642 dartings; 9 articles $(60 \%)$ do not report the number of unsuccessful dartings, i.e., "misses." Seven of the 15 articles (47\%) provide precise numbers on how immobilized individuals were physically retrieved.

Five of the six articles (83\%) providing general information (Category 2 of Cunningham et al. 2015) reported no injuries or deaths, and the remaining reported $4.6 \%$ of deaths and no information on injuries. These 6 articles describe 344 captures. They provide fewer details on darting procedures and do not include the number of individuals darted.

\section{Discussion}

We estimated a mean mortality rate of $2.5 \%$ and a nonfatal, serious injury rate of $1.5 \%$. Thus, our estimated mortality rate is smaller than the combined mortality and injury rate of 5\% reported by Cunningham et al. (2015) and smaller than the mortality rates of medium-sized terrestrial mammals used for comparison. Arnemo et al. (2006) report 
Table I Summary of the darting methods and results in the analyzed studies

\begin{tabular}{|c|c|c|c|c|c|c|}
\hline Study & $\begin{array}{l}\text { Darted } \\
\text { (hits) }\end{array}$ & Captured & $\begin{array}{l}\text { No. of } \\
\text { injuries }\end{array}$ & No. of deaths & $\%$ Injuries & $\%$ Deaths \\
\hline Scott et al. (1976) & N/A & 152 & 0 & $\begin{array}{c}3 \text { (2 due to } \\
\text { darting) }\end{array}$ & 0 & 1 \\
\hline Melton (1980) & 51 & 34 & 1 & $\begin{array}{c}2 \text { (1 due to } \\
\text { darting) }\end{array}$ & 3 & 3 \\
\hline Jones and Bush (1988) & 48 & 27 & 2 & 2 & 7 & 7 \\
\hline Glander et al. (1991) & N/A & 64 & 0 & 1 & 0 & 2 \\
\hline Richard et al. (1991) & N/A & 85 & 0 & 1 & 0 & 1 \\
\hline de Ruiter (1992) & N/A & 7 & 0 & 0 & 0 & 0 \\
\hline $\begin{array}{l}\text { Lemos de Sá and } \\
\text { Glander (1993) }\end{array}$ & N/A & 12 & 0 & 0 & 0 & 0 \\
\hline $\begin{array}{l}\text { Campbell and } \\
\text { Sussman (1994) }\end{array}$ & 8 & 7 & 0 & 1 & 0 & 14 \\
\hline $\begin{array}{l}\text { Mueller and } \\
\text { Schildger (1994) }\end{array}$ & N/A & 5 & 0 & 0 & 0 & 0 \\
\hline Hiong et al. (1996) & N/A & 50 & 0 & 2 & 0 & 4 \\
\hline Glenn et al. (1998) & 8 & 5 & 0 & 0 & 0 & 0 \\
\hline Karesh et al. (1998) & 11 & 9 & 1 & 1 & 11 & 11 \\
\hline Olupot (1999) & 47 & 41 & 2 & 2 & 0 & 5 \\
\hline $\begin{array}{l}\text { Fernandez-Duque and } \\
\text { Rotundo (2003) }\end{array}$ & N/A & 70 & 0 & 0 & 0 & 0 \\
\hline Crofoot et al. (2009) & N/A & 24 & 2 & 0 & 8 & 0 \\
\hline Horwich (2002) & N/A & 65 & N/A & 3 & N/A & 5 \\
\hline $\begin{array}{l}\text { Ostner and } \\
\text { Kappeler (2004) }\end{array}$ & N/A & 98 & 0 & 0 & 0 & 0 \\
\hline $\begin{array}{l}\text { Erkert and } \\
\quad \text { Kappeler (2004) }\end{array}$ & N/A & 8 & 0 & 0 & 0 & 0 \\
\hline $\begin{array}{l}\text { Andriantompohavana } \\
\text { et al. }(2004)\end{array}$ & N/A & 44 & 0 & 0 & 0 & 0 \\
\hline Donati et al. (2009) & N/A & 28 & 0 & 0 & 0 & 0 \\
\hline Tung et al. (2011) & N/A & 101 & 0 & 0 & 0 & 0 \\
\hline Total & 986 & 936 & 8 (6 serious) & $\begin{array}{l}18 \text { (16 due } \\
\text { to darting) }\end{array}$ & $1.5(\mathrm{SD}=3.3)$ & $2.5(\mathrm{SD}=4.0)$ \\
\hline
\end{tabular}

The full, detailed table is available as Supplementary Electronic Information (Table SI)

mortality rates $<2 \%$ only for large terrestrial mammals (moose, $0.7 \%$; bears, $0.9 \%$ ) and $>2 \%$ for medium-sized ones $(2.8 \%$, wolverines, $3.9 \%$ Eurasian lynx, $3.4 \%$ gray wolves, Table I). Based on these results, these authors suggest "that wildlife professionals should strive for a zero mortality rate but adopt the standard that a mortality rate of $>2 \%$ probably should not be accepted in any large [our emphasis] mammalian species" (p. 109). We agree with Cunningham et al. (2015) that primate researchers should strive for the lowest mortality rate possible, but we consider our estimates and theirs, when comparing across species, to be of little value and quite possibly 
misleading. Furthermore, these numbers can be potentially damaging when used in the wrong context.

Comparing statistics and methods across species can be useful and the sharing of information among researchers who study different species should be encouraged. However, although comparing models and statistics can be valuable, one needs to acknowledge and consider the differences between taxa, geographic regions, and research teams when developing taxon-specific protocols. Most primates are fairly small, arboreal animals, and therefore darting primates will unequivocally be different than darting large, terrestrial mammals. We propose that the first step should be to consolidate existing experience darting primates, which is extensive and spans all continents and a wide range of taxa (Fernandez-Duque and Rotundo 2003; Fernandez-Duque et al. 2000; Juárez et al. 2010; Glander 2013; Glander et al. 1991; Serio-Silva et al. 2015; Wasserman et al. 2013).

We did not delve into the ethics of darting, but rather evaluated it as a capture procedure. At this point, there are simply not enough details on darting to estimate accurately the risk that darting poses to primates. Therefore, we join Cunningham et al. (2015) and previous authors (Fedigan 2010) in calling for detailed descriptions of darting procedures and results. We encourage colleagues to include information on darting procedures, and for journals not only to allow, but also to encourage its inclusion. As seen in Sleeman et al. (2000) and Hyeroba et al. (2011), it will be increasingly necessary to capture primates to protect them from human activities, such as snaring. This will become increasingly difficult if experts do not provide detailed information on darting procedures, risks, and outcomes. Ultimately, and hopefully, greater communication and sharing of information among researchers will help mitigate any potential effects of our research on the well-being of primates.

Acknowledgments We thank J. Rothman, E. Cunningham, S. Evans, R. Cooper, J. C. Ruiz, C. R. Valeggia, and L. Williams for commenting on earlier versions of our manuscript. We extend special thanks to Elena Cunningham, Steve Unwin, and Joanna Setchell for providing us with article references, for clarifying questions we had about their work, and for their willingness to engage in a dialogue on a sensitive issue that we all care for similarly.

\section{References}

Akinyi, M. Y., Tung, J., Jeneby, M., Patel, N. B., Altmann, J., \& Alberts, S. C. (2013). Role of grooming in reducing tick load in wild baboons. Animal Behaviour, 85(3), 559-568.

Andriantompohavana, R., Randriamanana, J. C., Sommer, J. A., Brenneman, R. A., \& Louis Jr., E. E. (2004). Characterization of 22 microsatellite loci developed from the genome of the woolly lemur (Avahi laniger). Molecular Ecology Notes, 4(3), 400-403.

Arnemo, J. M., Ahlqvist, P., Andersen, R., Bernsten, F., Ericsson, G., et al (2006). Risk of capture-related mortality in large free-ranging mammals: Experiences in Scandinavia. Wildlife Biology, 12(1), 109-113.

Campbell, A. F., \& Sussman, R. W. (1994). The value of radio tracking in the study of neotropical rain-forest monkeys. American Journal of Primatology, 32(4), 291-301.

Crofoot, M. C., Norton, T. M., Lessnau, R. G., Viner, T. C., Chen, T. C., et al (2009). Field anesthesia and health assessment of free-ranging Cebus capucinus in Panama. International Journal of Primatology, 30(1), 125-141.

Cunningham, E. P., Unwin, S., \& Setchell, J. M. (2015). Darting primates in the field: A review of reporting trends and a survey of practices and their effect on the primates involved. International Journal of Primatology, 36(5), 894-915. 
de Ruiter, J. R. (1992). Capturing wild long-tailed macaques (Macaca fascicularis). Folia Primatologica, 59(2), 89-104.

Donati, G., Baldi, N., Morelli, V., Ganzhorn, J. U., \& Borgognini-Tarli, S. M. (2009). Proximate and ultimate determinants of cathemeral activity in brown lemurs. Animal Behaviour, 77(2), 317-325.

Erkert, H. G., \& Kappeler, P. M. (2004). Arrived in the light: Diel and seasonal activity patterns in wild verreaux's sifakas (Propithecus v. verreauxi; primates: Indriidae). Behavioral Ecology and Sociobiology, 57(2), 174-186.

Fedigan, L. M. (2010). Ethical issues faced by field primatologists: Asking the relevant questions. American Journal of Primatology, 72(9), 754-771.

Fernandez-Duque, E., \& Erkert, H. G. (2006). Cathemerality and lunar periodicity of activity rhythms in owl monkeys of the Argentinian Chaco. Folia Primatologica, 77(1-2), 123-138.

Fernandez-Duque, E., \& Rotundo, M. (2003). Field methods for capturing and marking azarai night monkeys. International Journal of Primatology, 24(5), 1113-1120.

Fernandez-Duque, E., Valeggia, C., \& Mason, W. A. (2000). Effects of pair-bond and social context on malefemale interactions in captive titi monkeys (Callicebus moloch, primates: Cebidae). Ethology, 106, 10671082.

Glander, K. (2013). Darting, anesthesia, and handling. In E. J. Sterling, N. Bynum, \& M. E. Blair (Eds.), Primate ecology and conservation. Oxford: Oxford University Press.

Glander, K. E., Fedigan, L. M., Fedigan, L., \& Chapman, C. (1991). Field methods for capture and measurement of three monkey species in Costa Rica. Folia Primatologica, 57(2), 70-82.

Glenn, M. E., \& Bensen, K. J. (1998). Capture techniques and morphological measurements of the mona monkey (Cercopithecus mona) on the island of Grenada, West Indies. American Journal of Physical Anthropology, 105(4), 481-491.

Hiong, L. K., Sale, J. B., \& Andau, P. M. (1996). Capture of wild orangutan by drug immobilization. Tropical Biodiversity, 3(2), 103-113.

Horwich, R. H., Koontz, F., Saqui, E., Ostro, L., Silver, S., \& Glander, K. (2002). Translocation of black howler monkeys in Belize. Re-introduction NEWS, 21, 10-12.

Hyeroba, D., Apell, P., \& Otali, E. (2011). Managing a speared alpha male chimpanzee (Pan troglodytes) in Kibale National Park, Uganda. Veterinary Record, 169(25), 658.

Jones, W. T., \& Bush, B. B. (1988). Darting and marking techniques for an arboreal forest monkey, Cercopithecus ascanius. American Journal of Primatology, 14(1), 83-89.

Juárez, C. P., Rotundo, M. A., Berg, W., \& Fernandez-Duque, E. (2010). Costs and benefits of radio-collaring on the behavior, demography, and conservation of owl monkeys (Aoutus Azarai). International Journal of Primatology, 32(1), 69-82.

Kappeler, P. M., \& Erkert, H. G. (2003). On the move around the clock: Correlates and determinants of cathemeral activity in wild red fronted lemurs (Eulemur fulvus rufus). Behavioral Ecology and Sociobiology, 54(4), 359-369.

Karesh, W. B., Wallace, R. B., Painter, R. L., Rumiz, D., Braselton, W. E., et al (1998). Immobilization and health assessment of free-ranging black spider monkeys (Ateles paniscus chamek). American Journal of Primatology, 44(2), 107-123.

Lemos de Sá, R. M., \& Glander, K. E. (1993). Capture techniques and morphometrics for the woolly spider monkey, of muriqui, (Brachyteles arachnoides) E. Geoffroy 1806. American Journal of Primatology, 29(2), 145-153.

Melton, D. A. (1980). Baboon (Papio ursinus) capture using a blow-dart system. South African Journal of Wildlife Research, 10, 67-70.

Mueller, K. H., \& Schildger, J. (1994). Capture and radio-telemetry of masked titi monkeys, Callicebus personatus melanochir. Neotropical Primates, 2(4), 7-8.

Olupot, W. (1999). Darting, individual recognition, and radio-tracking techniques in grey-cheeked mangabeys Lophocebus albigena of Kibale National Park, Uganda. African Primates, 4(1-2), 40-50.

Ostner, J., \& Kappeler, P. M. (1999). Central males instead of multiple pairs in redfronted lemurs, Eulemur fulvus rufus (primates, Lemuridae)? Animal Behaviour, 58(5), 1069-1078.

Ostner, J., \& Kappeler, P. M. (2004). Male life history and the unusual adult sex ratios of red fronted lemur, Eulemur fulvus rufus, groups. Animal Behaviour, 67(2), 249-259.

Port, M., Clough, D., \& Kappeler, P. M. (2009). Market effects offset the reciprocation of grooming in freeranging red fronted lemurs, Eulemur fulvus rufus. Animal Behaviour, 77(1), 29-36.

Richard, A. F., Rakotomanga, P., \& Schwartz, M. (1991). Demography of Propithecus verreauxi at Beza Mahafaly, Madagascar: Sex ratio, survival, and fertility, 1984-1988. American Journal of Physical Anthropology, 84(3), 307-322. 
Schultz, A. H. (1937). Proportions, variability and asymmetries of the long bones of the limbs and the clavicles in man and apes. Human Biology, 9(3), 281-328.

Scott, N. J., Scott, A. F., \& Malmgren, L. A. (1976). Capturing and marking howler monkeys for field behavioral studies. Primates, 17(4), 527-533.

Serio-Silva, J. C., Olguín-Palacios, E., Garcia-Feria, L., Tapia-Fierro, K. L., \& Chapman, C. A. (2015). Cascading impacts of anthropogenically driven habitat loss: Deforestation, flooding, and possible lead poisoning in howler monkeys (Alouatta pigra). Primates, 56, 29-35.

Sleeman, J. M., Cameron, K., Mudakikwa, A. B., Nizeyi, J. B., Anderson, S., et al (2000). Field anesthesia of free-living mountain gorillas (Gorilla gorilla beringei) from the Virunga volcano region, Central Africa. Journal of Zoo and Wildlife Medicine, 31(1), 9-14.

Tung, J., Akinyi, M. Y., Mutura, S., Altmann, J., Wray, G. A., \& Alberts, S. C. (2011). Allele-specific gene expression in a wild nonhuman primate population. Molecular Ecology, 20(4), 725-739.

Wasserman, M. D., Chapman, C. A., Milton, K., Goldberg, T. L., \& Ziegler, T. E. (2013). Physiological and behavioral effects of capture darting on red colobus monkeys (Procolobus rufomitratus) with a comparison to chimpanzee predation. International Journal of Primatology, 34, 1020-1031.

Wimmer, B., \& Kappeler, P. M. (2002). The effects of sexual selection and life history on the genetic structure of redfronted lemur, Eulemur fulvus rufus, groups. Animal Behaviour, 64(4), 557-568. 